\title{
Two Quantitative Evaluation Methods for Identifying the Migration Pathways in Hydrocarbon Carrier: Application and Comparison
}

\author{
Wang Kun* and Hu Suyun
}

\author{
Research Institute of Petroleum Exploration and Development, PetroChina, Beijing, 100083, P.R. China
}

\begin{abstract}
Carrier is an important media linking source rocks and reservoirs. In the past two decades, it is the hot topic for the hydrocarbon geology researchers. Migration pathways in carrier are main space for the hydrocarbon migration. The identification of these pathways has great meaning for the hydrocarbon exploration. In this paper, we define a pathway as a macroscopical area in any shape that relatively apparent hydrocarbon migration exists in the carrier according to some research methods. The sandstone carrier of the Neogene Shawan formation and the unconformity carrier of the Cretaceous being located in the Chepaizi uplift of the Junggar Basin (NW China) are selected as research objects. We used quantitative grain fluorescence analysis (QGF) and effective migration thickness analysis (EMT) to quantitatively study these two kinds of pathways. Migration characteristics of the hydrocarbons are analyzed in single wells and in plane. Analysis results show that evaluation and prediction results from two methods are very similar. This verifies the feasibility of those methods for pathways analysis. Based on the calibration of commercial oil flow well, distribution of migration pathways in plane is obtained, which narrow down the exploration areas. Through practical application, the application process and the considerations of the two methods are discussed and compared. For sandstone carrier, the thickness can be obtained from well logging reports and well logging diagrams. Precondition that the samples collected are located in the carrier interval in QGF analysis is needed. For unconformity carrier, identification of the unconformity surfaces is an important basic work. Increasing the sampling density can reduce the analytical errors caused by the inhomogeneous distribution of oil. EMT method is simple; however, the precondition for application is that the oil in the carrier is not too light and is well preserved in geology history.
\end{abstract}

Keywords: Carrier, Effective migration thickness analysis, Migration pathways, Quantitative grain fluorescence analysis.

\section{INTRODUCTION}

Carrier which links source rocks and traps is an essential ingredient of the petroleum system $[1,2]$. Heterogeneity of the carriers results in the complexity of hydrocarbon migration in them $[3,4]$. Though the distribution of carriers mostly is planar and continuous, only part of the carriers with porous media called pathways participates in the hydrocarbon migration $[5,6]$. Finding and assessing these pathways starting from source rock is one of the most important tasks for the hydrocarbon exploration. In the past two decades, many scholars have studied the pathways through geology, geochemistry, physical modeling and numerical simulation methods [7-10]. Geology method uses the well logging data, drilling data, and seismic data to describe the distribution and the characteristics of the pathways. Oil-source correlation data, fluid inclusion analysis data were applied for the identification of migration direction and the location of pathways in geochemistry method. On the basis of similarity principle, physical modeling method builds the models of geology body and simulates the migration of hydrocarbon in the pathways. Based on geological and geochemical analysis, numerical simulation method combines energy field with kinetics of hydrocarbon generation and rebuild the entire hydrocarbon migrating process.

*Address correspondence to this author at the Research Institute of Petroleum Exploration and Development, PetroChina, Beijing, 100083, P.R. China; Tel:+8610 83595700; E-mail: wangkuntoby@163.com
Ideally, after expelled into the carriers, hydrocarbons first vertically migrate toward the top of the carriers where small spaces near the top correspondingly become pathways. The hydrocarbons just occupy 1 to $10 \%$ in volume when they go through the carriers, even in confine homogeneous media [11-13]. Though defining pathways as narrow channels that maximumly account for $10 \%$ of the carriers is suitable for physical and numerical simulation and laboratory scale studies, it could create difficulties in the geology study of tectonic zone scales. In tectonic zone scales, identifying the narrow channels for hydrocarbon migration is difficult to achieve and unpractical. In this study, we treated pathway as a macroscopical area in any shape that relatively apparent hydrocarbon migration exists in the carrier according to some research methods. Commonly, there are two opposite entry points for the research of hydrocarbon migration and pathways: one is focusing on characteristics of the pathways, such as quality, occurrence and heterogeneity; the other is focusing on the occurrence of the hydrocarbon in the carrier, such as quantity, distribution and microcosmic characteristics. According to the former one, researchers can objectively evaluate the entire pathways in the carriers and obtain their capacity for migration; however, relatively low driving force and supplement of hydrocarbon usually result in the partial ineffectivity of the pathways, even those pathways indeed have good capacity for migration. On the basis of the latter one, researchers can confirm the effectivity of the pathways according to the existence of hydrocarbon; howev- 
er, enough drilling data are needed for guaranteeing the accuracy of the evaluation. In this paper, we choose the Chepaizi uplift in the western Junggar Basin (NW China) as the application area and use two quantitative methods focusing on the hydrocarbon to study two different carriers (sandstone carrier and unconformity carrier) of the oil reservoirs. One is Quantitative grain fluorescence analysis (QGF); the other is effective migration thickness analysis (EMT). Based on the study, application effects of these two methods were discussed and compared and favorable exploration areas were obtained.

\section{GEOLOGIAL SETTING OF THE RESEARCH AR- EA}

The Chepaizi uplift located in the western margin of the Junggar Basin is a secondary tectonic unit with dip direction of SE. It is illustrated in Fig. (1). Formed by the Hercynian movement, the Chepaizi uplift successively experienced intense uplift, slow subsidence and rapid subsidence stages, and now is a wide and gentle slope [14-17]. With Carboniferous volcanics ranging of 150 to 2300 buried depth as basement, the uplift from bottom to top develops the Jurassic, Cretaceous, Paleogene, Neogene and Quaternary that all pinch out toward the NW, missing the Permian and Triassic. The Permian in the Changji depression are the oil source for the heavy oil accumulating in the lithologic- stratigraphic traps [18-20]. There are two primary oil-bearing strata: the Cretaceous and the Neogene Shawan formation. Hydrocarbons in the Cretaceous mainly accumulate in the lacustrine facies isolated porous thin sandstone with bottom unconformity as the carrier [21]. Braid river delta sandstone extensively developing in the bottom of the Shawan formation is the most important carrier for the oil reservoirs also in the Shawan formation [22, 23]. The oil reservoirs in the Chepaizi uplift are 60 to $120 \mathrm{~km}$ far from the sources; as a result, accumulation driving force is not enough for the effectivity and high filling degree of all traps [24]. Therefore, pathway is the main factor controlling the distribution of the hydrocarbons.

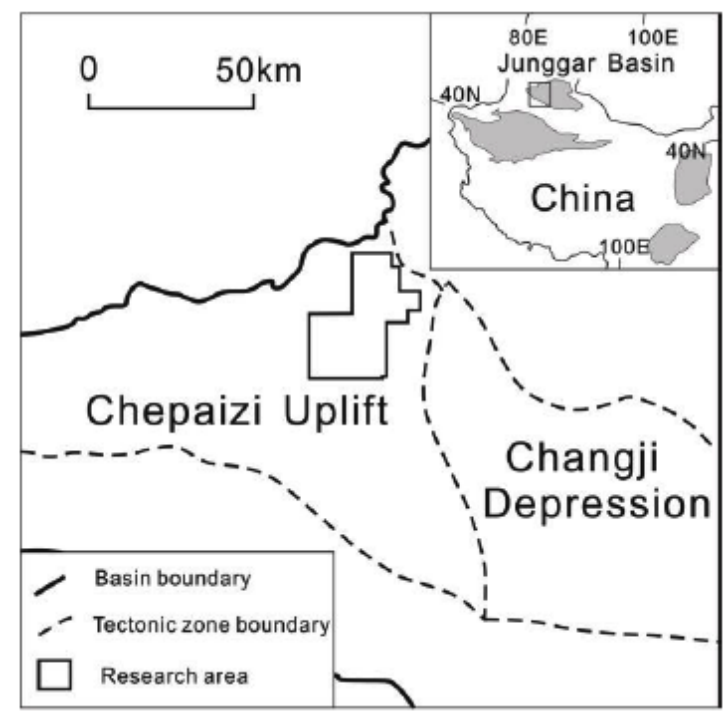

Fig. (1). Classification of the tectonic units in the west Junggar Basin and location diagram of the research area.

\section{MATERIAL AND METHOD}

\subsection{Quantitative Grain Fluorescence Techniques}

Quantitative grain fluorescence (QGF) is developed for detecting both current (residual) and palaeo oil in petroleum reservoirs in single analytical procedure without destroying samples [25-28].

50 core or cutting samples of the Neogene Shawan formation from 20 wells and 13 core or cutting samples of the Cretaceous from 4 wells were conducted on the QGF analysis. All the samples were firstly disaggregated into individual grains and then were sieved to select the sand fraction $(63 \mu \mathrm{m}-1 \mathrm{~mm})$. Two gram grains were dipped in dichloromethane (DCM) with ultrasound bath for $10 \mathrm{~min}$. After being dried by oven at 60 Celsius, samples were dissolved in $10 \% \mathrm{H}_{2} \mathrm{O}_{2}$ with initial and final $10 \mathrm{~min}$ ultrasound bath. Then, grains were dipped in $3.6 \%$ hydrochloric acid with periodic agitation for $20 \mathrm{~min}$ followed by oven dried. The remaining grains are washed a second time with DCM in an ultrasonic bath for $10 \mathrm{~min}$ to extract hydrocarbon compounds adhering on the grain surface. QGF is measured on dry grains. A Cary-Eclipse fluorescence spectrophotometer was used for QGF [29].

One of the significant parameters used for the study is QGF index [30]. QGF index is the average spectral intensity between $375 \mathrm{~nm}$ and $475 \mathrm{~nm}$ normalized to the spectral intensity at $300 \mathrm{~nm}$. QGF index can reflect the hydrocarbon migration cases. In this paper, characteristics and distributions of the QGF index in single well were firstly analyzed to evaluate the 1- dimension vertical hydrocarbon migration. If more than one samples were collected and analyzed in single well, the QGF index of that well is obtained by arithmetic average. When QGF index of each well was obtained, QGF index' contour maps of the two different carriers were drawn to identify the possible pathway in plane.

\subsection{Effective Migration Thickness Analysis}

Geological logging including core logging, cutting logging, fluorescent logging and gas logging estimates the hydrocarbon cases in the wells. Hydrocarbon migration more or less left traces which result in the hydrocarbon show in the geological logging [30]. Therefore, hydrocarbon show in geological logging can be used to study the distribution of pathways. Generally, hydrocarbon shows are divided into several ranks according to different standards, customs and geology settings. In China, based on the geology logging regulations for oil and gas exploration wells (SY/T 5788.31999) which belong to Oil and Gas Industry Standards of China, 6 ranks are classified to describe the oil shows: oil saturated (OS), oil rich (OR), oil filled (OF), oil patch (OP), oil trace (OT), and oil fluorescence (OL) (Table 1).

We proposed effective migration thickness (EMT) to describe the migrating capacity of carrier in single well and further study the carrier in the plane. EMT is defined as the weighting thickness of oil show intervals inner the carrier.

$\mathrm{EMT}=\left(\mathrm{c}_{1} \cdot \mathrm{h}_{\mathrm{OS}}+\mathrm{c}_{2} \cdot \mathrm{h}_{\mathrm{OR}}+\mathrm{c}_{3} \cdot \mathrm{h}_{\mathrm{OF}}+\mathrm{c}_{4} \cdot \mathrm{h}_{\mathrm{OP}}+\mathrm{c}_{5} \cdot \mathrm{h}_{\mathrm{OT}}+\mathrm{c}_{6} \cdot \mathrm{h}_{\mathrm{OL}}\right)$

Where,

$h$--- the thickness of the oil shows inner the carrier, m; 
$c_{1}, c_{2}, c_{3}, c_{4}, c_{5}, c_{6}$--- the weighting values

Two parameters need to be considered here: weighting value and total carrier thickness. Weighting values can be determined using different criteria, such as percentage of oilbearing area, oil feeling, smelling and dripping test. In this study, the weighting values of the oil shows are based on the percentage of oil-bearing area in Table 1. Here, the values of $\mathrm{c}_{1}, \mathrm{c}_{2}, \mathrm{c}_{3}, \mathrm{c}_{4}, \mathrm{c}_{5}, \mathrm{c}_{6}$ respective are $1,0.8,0.6,0.4,0.2$, and 0.1 . For sandstone carrier, identifying the lithology interfaces can easily determine the thickness of carrier. For unconformity carrier, cores and well logging responses are important data for the identification of the unconformity interfaces $[31,32]$. Ideally, the unconformity has a three-layer structure in space. From top to bottom, the layers respectively are the rocks above the unconformity plane, the weathered clay beneath the unconformity plane and the semi-weathered rocks beneath the clay [33]. In the Chepaizi uplift, the unconformity between the Cretaceous and underlying strata is due to the two intervals with weather clay interval absent. The rocks above the unconformity plane are dominated by lacustrine transgressive siltstone and mudstone. The self-potential (SP) curve of this interval occurs at low degree negative drift with gentle bend. The acoustic times (AC) show almost no abnormality while the dual induction logging curves (RILD and RILM) increase with little separation. The underlying strata unconformable to the Cretaceous contain Jurassic breccia or the Carboniferous tuff. Electrical responses curves have different characteristics for different lithology. Semiweathered rocks of breccia show negative drift on SP curve. The acoustic times are relatively high than the lower parts and gradually decrease. The dual induction logging curves get separated from each other with relatively high value. Semi-weathered rocks of tuff also show negative drift on SP curve. The acoustic time curves are low and straight. The dual induction logging curves gradually increase with complex shapes and low degree separation.

Table 1. Result of experiments and theory.

(1-1)

\begin{tabular}{|c|c|c|c|}
\hline Oil Show Rank & Oil Saturated & Oil Rich & Oil Filled \\
\hline \hline $\begin{array}{c}\text { Percentage of } \\
\text { oil-bearing area }\end{array}$ & $>95 \%$ & $>70 \sim 95$ & $>40 \sim 70$ \\
\hline
\end{tabular}

(1-2)

\begin{tabular}{|c|c|c|c|}
\hline Oil Show Rank & Oil Patch & Oil Trace & $\begin{array}{c}\text { Oil Fluores- } \\
\text { cence }\end{array}$ \\
\hline \hline $\begin{array}{c}\text { Percentage of } \\
\text { oil-bearing area }\end{array}$ & $>5 \sim 40$ & $<5$ & 0 \\
\hline
\end{tabular}

23 wells were conducted on the EMT analysis of the sandstone carrier in the Shawan formation and 18 wells were conducted on the EMT analysis of the unconformity carrier in the Cretaceous. The lithology sections of these wells were firstly calibrated by the logging and core data, ensuring the correction of the oil shows thickness. When thicknesses of the carriers and oil shows were confirmed on single well, EMTs were correspondingly calculated.

\section{RESULTS}

\subsection{QGF Analysis of the Sandstone Carrier}

Results of the QGF analysis for the sandstone carrier of the Neogene Shawan formation are shown in Table 2.

Table 2. Results of the QGF analysis of the sandstone carrier in the Neogene Shawan formation.

(1-1)

\begin{tabular}{|c|c|c|c|}
\hline Sample No. & Well & $\begin{array}{l}\text { Measured } \\
\text { Depth (m) }\end{array}$ & $\begin{array}{l}\text { QGF Index } \\
\text { (pc) }\end{array}$ \\
\hline 1 & $\mathrm{P} 1$ & 213.00 & 3.09 \\
\hline 2 & $\mathrm{P} 1$ & 218.50 & 3.25 \\
\hline 3 & P1 & 223.00 & 3.02 \\
\hline 4 & P103 & 229.00 & 5.25 \\
\hline 5 & P103 & 231.50 & 3.36 \\
\hline 6 & P103 & 233.50 & 5.32 \\
\hline 7 & P6 & 430.00 & 4.02 \\
\hline 8 & P6 & 431.50 & 3.97 \\
\hline 9 & P6 & 432.00 & 3.58 \\
\hline 10 & P60 & 185.00 & 4.02 \\
\hline 11 & P60 & 195.00 & 5.28 \\
\hline 12 & P60 & 205.50 & 4.55 \\
\hline 13 & P60 & 215.50 & 4.48 \\
\hline 14 & P601 & 488.00 & 5.45 \\
\hline 15 & P601 & 489.00 & 5.26 \\
\hline 16 & P601 & 492.00 & 5.08 \\
\hline 17 & P603 & 355.00 & 3.57 \\
\hline 18 & P604 & 630.50 & 4.38 \\
\hline 19 & P604 & 635 & 3.35 \\
\hline 20 & P604 & 637.5 & 2.90 \\
\hline 21 & P605 & 395.5 & 3.99 \\
\hline 22 & P605 & 401.5 & 4.56 \\
\hline 23 & P606 & 655 & 3.38 \\
\hline 24 & P606 & 660 & 4.14 \\
\hline 25 & P608 & 263.5 & 3.68 \\
\hline 26 & P608 & 265.5 & 3.6 \\
\hline 27 & P608 & 267 & 4.35 \\
\hline 28 & P609 & 228 & 4.91 \\
\hline 29 & P61 & 258 & 4.74 \\
\hline 30 & P61 & 263 & 3.30 \\
\hline 31 & P61 & 269 & 4.60 \\
\hline 32 & P610 & 403 & 3.49 \\
\hline
\end{tabular}


(Table 2) contd....

(1-2)

\begin{tabular}{|c|c|c|c|}
\hline Sample No. & Well & Measured Depth (m) & QGF Index (pc) \\
\hline 33 & P610 & 409 & 4.30 \\
\hline 34 & P610 & 412 & 3.69 \\
\hline 35 & P611 & 484 & 4.6 \\
\hline 36 & P612 & 310.5 & 4.76 \\
\hline 37 & P613 & 290.5 & 5.58 \\
\hline 38 & P613 & 293 & 4.82 \\
\hline 39 & P613 & 296 & 4.17 \\
\hline 40 & P614 & 502.5 & 3.52 \\
\hline 41 & P614 & 507.5 & 3.45 \\
\hline 42 & P62 & 78.5 & 3.21 \\
\hline 43 & P62 & 84 & 2.95 \\
\hline 44 & P63 & 105 & 3.64 \\
\hline 45 & P63 & 110 & 2.87 \\
\hline 46 & P63 & 115 & 3.05 \\
\hline 47 & $\mathrm{C} 1-7$ & 561.5 & 4.77 \\
\hline 48 & $\mathrm{C} 1-7$ & 563.5 & 4.78 \\
\hline 49 & $\mathrm{C} 1-7$ & 568 & 5.13 \\
\hline 50 & $\mathrm{C} 1-7$ & 569 & 3.83 \\
\hline
\end{tabular}

The distribution of the QGF index in single well is shown in Fig. (2). Some wells (P601, etc.) have high QGF indexes with little differences in different depths of the sandstone carrier, which indicates that these wells are located on the important pathways for hydrocarbon migration. Some wells (P604, P613, P61, etc.) have same lithology in different depths of the carrier; however, QGF indexes show obvious differences. This indicates that only part of the carrier in these wells contributed to the hydrocarbon migration. For example, the QGF indexes of the P604 decrease with the increase of the depth, indicating that hydrocarbon was affected by buoyancy during the long distance migration and only the top part of the carrier became pathways. The QGF indexes of the P61 are irregular in depth section. This shows that there are impermeable laminated intervals which result in secondary pathways. Some wells (such as P601 and P614) that are close to each other are obviously different in the characteristics of the QGF indexes. The QGF indexes in P601's coarse sandstone are higher than 5 photometer counts (pc) whereas the QGF indexes are around 3.8pc in P606 with same lithology, indicating that pathways in P601 are more efficient than P614.

Fig. (3) is the contour map of the QGF index reflecting the hydrocarbon migration and the pathways in the plane. The QGF index values reduce from the SE to the NW, indicating that the hydrocarbon is from the SE. P612, P613 and P60 in the northern part of the study region have high QGF index values (higher than $5 \mathrm{pc}$ ). The central region where P606, P604 and P602 located has high QGF index values and larger high-value area than the northern part. It suggests that this area has relatively obvious hydrocarbon migration which can be treated as possible pathways.

\subsection{EMT Calculation of the Sandstone Carrier}

EMTs of the sandstone carrier are shown in Table 3.

The sandstone carrier of the Shawan formation ranges in thickness from 4 to $40 \mathrm{~m}$ with most values concentrating between 10 to $30 \mathrm{~m}$. EMTs range from 0 to $6.2 \mathrm{~m}$ and have no apparent relationship with the sandstone thickness. Oil patch
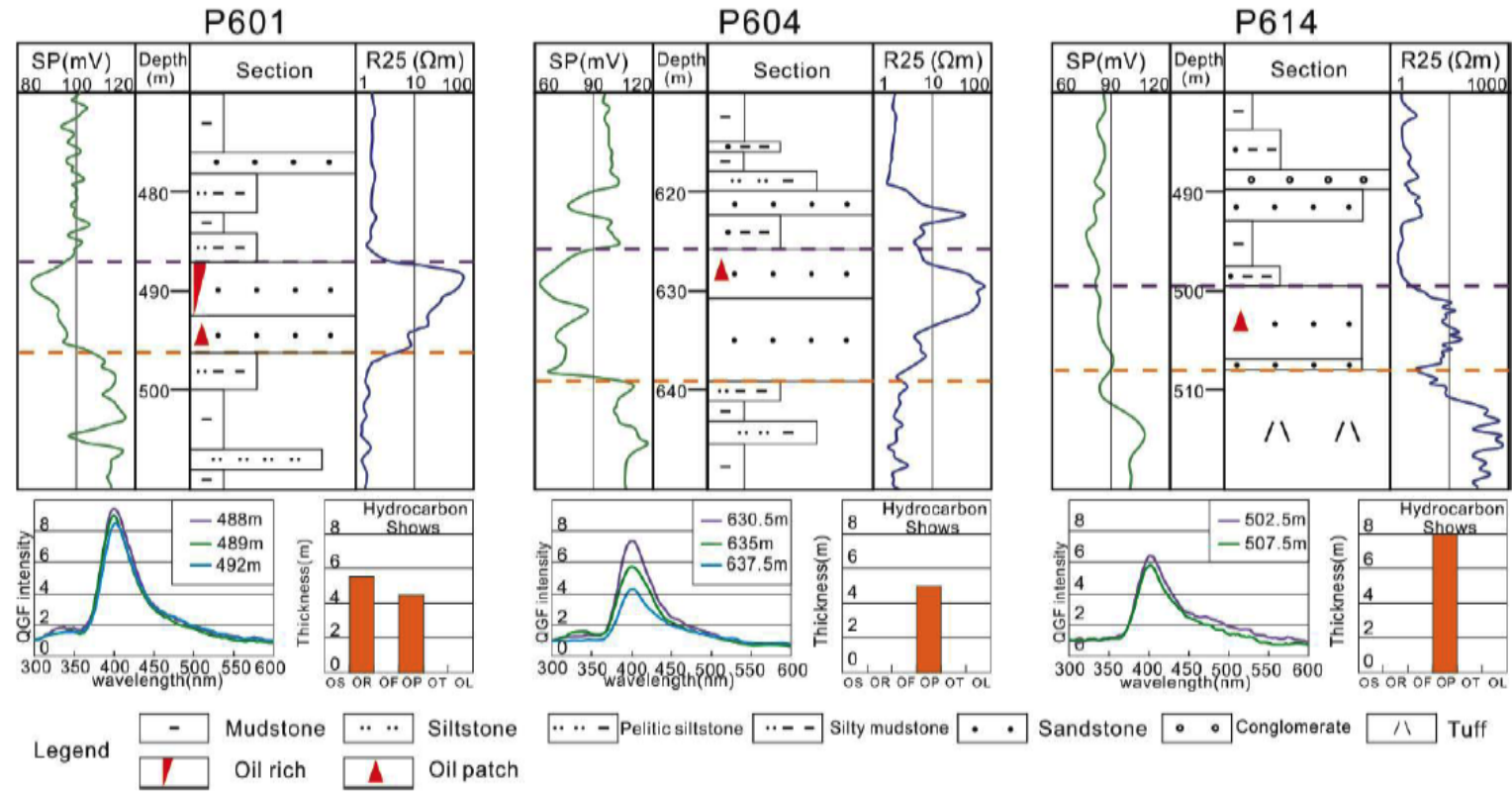

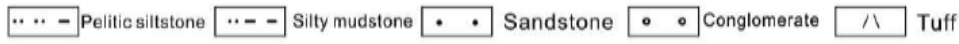

Fig. (2). Lithology, well logging depth profiles, spectra and oil shows of the sandstone carrier in P601, P604 and P614. 
is the most common oil show range while no well has oil saturated intervals. In single well, the distribution of the oil shows is not uniform in large continuous sandstone. In general, the interval near the top has higher oil show rank, which is similar to the distribution characteristics of the QGF. This indicates that buoyancy plays an important role in the secondary migration process. As shown in Fig. (4), the contour map of the EMT has two high value areas; P605 and P612 in the middle region and $\mathrm{P} 601$ and $\mathrm{C} 1-7$ in the south region have high EMT values which respectively face toward the NW and $\mathrm{W}$ directions. This indicates that there are two possible pathways located in the middle and south of the study area.

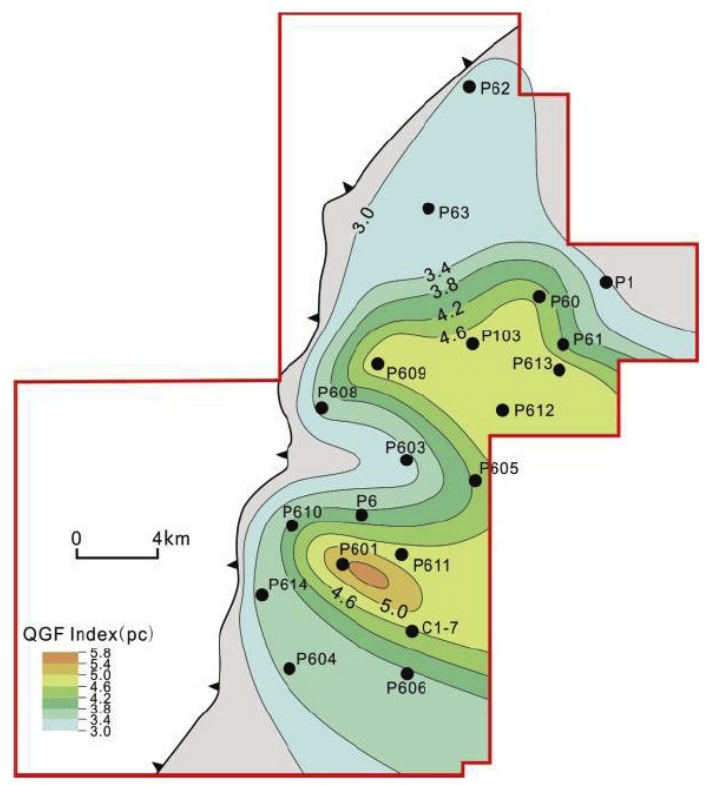

Fig. (3). Contour map of the QGF Index of the sandstone carrier.

Table 3. The EMT of the sandstone in the Neogene Shawan formation.

\begin{tabular}{|c|c|c|c|c|c|}
\hline Well & $\begin{array}{c}\text { Sandstone } \\
\text { Thickness (m) }\end{array}$ & EMT(m) & Well & $\begin{array}{c}\text { Sandstone } \\
\text { Thickness (m) }\end{array}$ & EMT(m) \\
\hline \hline P6 & 5.5 & 1.5 & C1-7 & 32 & 4 \\
\hline P61 & 19.5 & 0.5 & C1-8 & 27 & 3.2 \\
\hline P609 & 18 & 3 & P604 & 27.5 & 2.6 \\
\hline P608 & 15 & 1.5 & P1 & 22.5 & 0 \\
\hline P607 & 15.5 & 2.75 & P103 & 13 & 0 \\
\hline P612 & 20.5 & 5.8 & P606 & 40 & 0 \\
\hline P603 & 3 & 1.2 & P614 & 9 & 3.2 \\
\hline P605 & 20.5 & 6.1 & P604 & 18.5 & 2 \\
\hline P610 & 10.5 & 3.25 & P618 & 18 & 3.2 \\
\hline P601 & 23.5 & 6.2 & P63 & 7 & 0.6 \\
\hline P611 & 11 & 3.5 & P62 & 4 & 0.4 \\
\hline P602 & 19.5 & 3.4 & & & \\
\hline
\end{tabular}

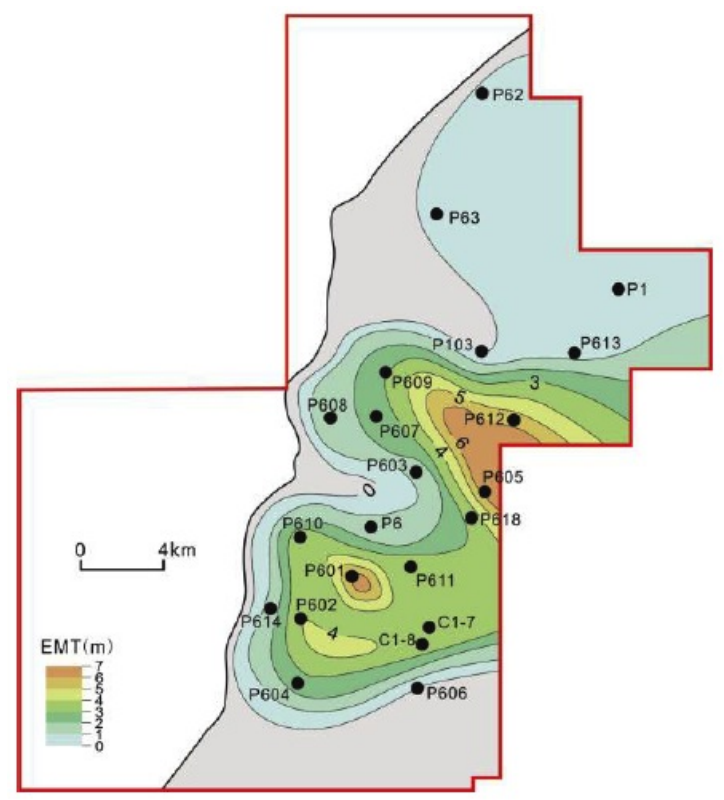

Fig. (4). Contour map of the EMT of the sandstone carrier.

\subsection{QGF Analysis of the Unconformity Carrier}

Results of the QGF analysis for the unconformity carrier in the Cretaceous are shown in Table 4.

Table 4. Results of the QGF analyses of the unconformity carrier in the Cretaceous.

\begin{tabular}{|c|c|c|c|}
\hline Sample No. & Well & $\begin{array}{c}\text { Measured } \\
\text { Depth (m) }\end{array}$ & $\begin{array}{c}\text { QGF Index } \\
\text { (pc) }\end{array}$ \\
\hline \hline 1 & $\mathrm{P} 607$ & 355.5 & 5.66 \\
\hline 2 & $\mathrm{P} 607$ & 360 & 4.97 \\
\hline 3 & $\mathrm{P} 607$ & 365.5 & 5.87 \\
\hline 4 & $\mathrm{P} 605$ & 728.5 & 1.88 \\
\hline 5 & $\mathrm{P} 605$ & 733 & 2.77 \\
\hline 6 & $\mathrm{P} 605$ & 751.5 & 2.65 \\
\hline 7 & $\mathrm{P} 605$ & 769 & 1.54 \\
\hline 8 & $\mathrm{P} 610$ & 410.5 & 2.15 \\
\hline 9 & $\mathrm{P} 610$ & 415 & 2.28 \\
\hline 10 & $\mathrm{P} 610$ & 417 & 1.84 \\
\hline 11 & $\mathrm{P} 602$ & 566 & 3.85 \\
\hline 12 & $\mathrm{P} 602$ & 568 & 4.06 \\
\hline 13 & $\mathrm{P} 602$ & 581 & 3.47 \\
\hline
\end{tabular}

In single well, the QGF index distribution of the unconformity carrier is a little different from the sandstone carrier. QGF values show no significant change law with the increase of depth, which indicates that the unconformity carrier is inhomogeneous. As can be seen in Fig. (5), the existence of mudstone leads to the weakness of the QGF's 


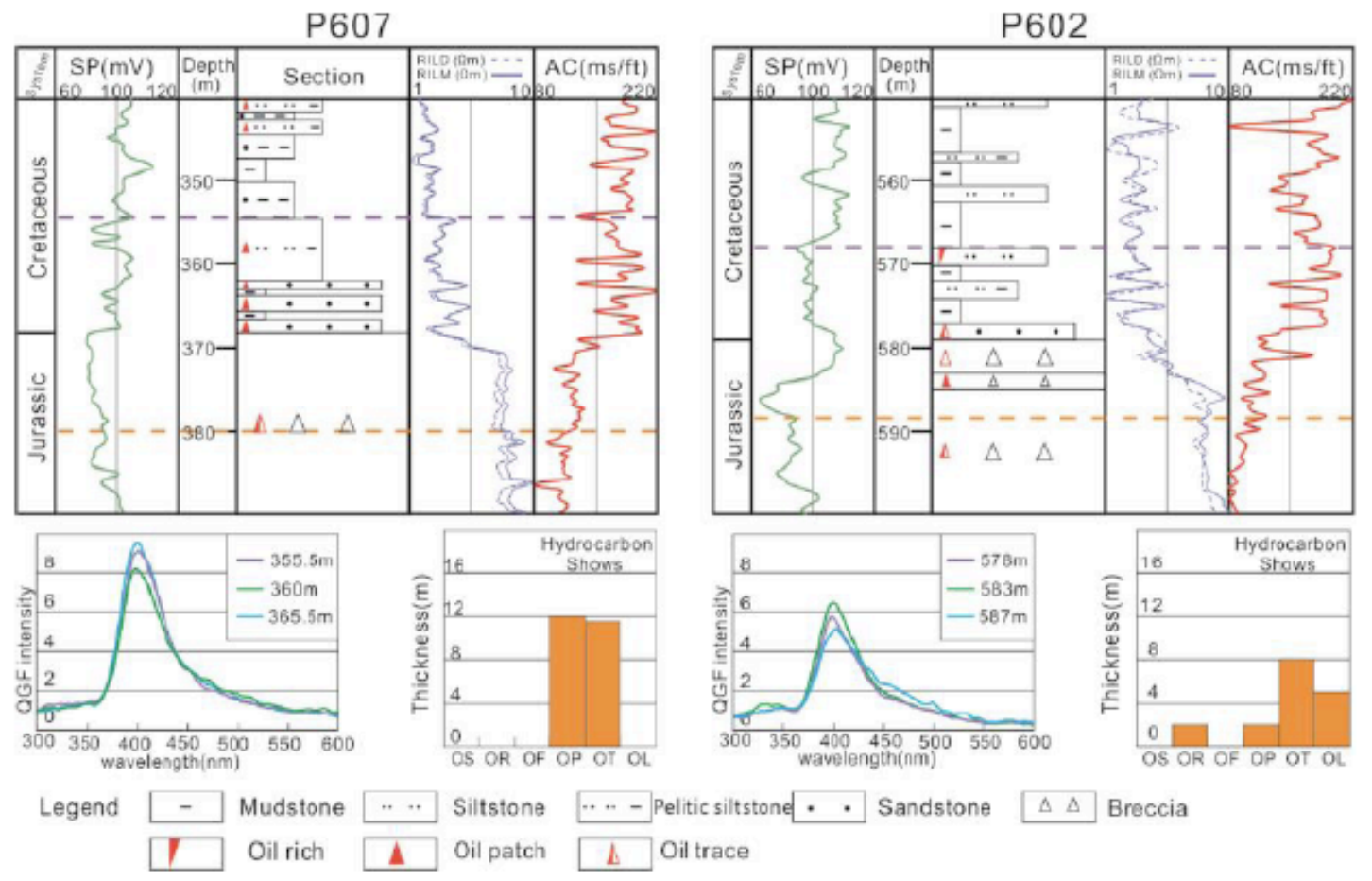

Fig. (5). Lithology, well logging depth profiles, spectra and oil shows of the unconformity carrier in P601 and P604.

vertical differentiation; however, intervals near the top still have relatively high QGF value. Only 4 wells were analyzed in the study, through which it is difficult to draw the contour map. However, they are valuable information for checking the availability of EMT method.

\subsection{EMT Calculation of the Unconformity Carrier}

EMTs of the unconformity carrier are shown in Table 5.

Table 5. EMT of the unconformity carrier in the Cretaceous.

\begin{tabular}{|c|c|c|c|c|c|}
\hline Well & $\begin{array}{c}\text { Sandstone } \\
\text { Thickness (m) }\end{array}$ & EMT(m) & Well & $\begin{array}{c}\text { Sandstone } \\
\text { Thickness (m) }\end{array}$ & $\begin{array}{c}\text { EMT } \\
(\mathbf{m})\end{array}$ \\
\hline \hline P1 & 19 & 8.10 & P606 & 29 & 8.40 \\
\hline P6 & 18 & 3.10 & P607 & 25.5 & 7.10 \\
\hline P60 & 24.5 & 4.10 & P609 & 21.5 & 4.80 \\
\hline P103 & 27 & 5.20 & P610 & 9.5 & 0.60 \\
\hline P601 & 14.5 & 0.80 & P612 & 27.5 & 2.50 \\
\hline P602 & 20.5 & 4.50 & P613 & 18 & 2.60 \\
\hline P603 & 25.5 & 0.80 & C1-7 & 23.5 & 9.40 \\
\hline P604 & 12 & 2.80 & C1-8 & 27 & 7.90 \\
\hline P605 & 23.5 & 0.90 & C1 & 18 & 2.40 \\
\hline
\end{tabular}

The thickness of the unconformity ranges from 9.5 to $27 \mathrm{~m}$ and the EMT ranges from 0.8 to $9.4 \mathrm{~m}$. The mudstone divided the unconformity into several secondary pathways. The oil migration is not limited to the upper interval of the carrier. In Fig. (6), two migration directions can be identified in the contour map of the EMT. The north high value area extends SW-ward from P1 to P6. In the vicinity of the P1, the EMTs are larger than $8 \mathrm{~m}$, which face toward the SW. The south high value area includes C1-7, C1-8, P606, P602 and P604 and extends NW-ward. It indicates that there have two possible pathways for the migration of the hydrocarbon in the unconformity carrier. The conclusion can be verified by the QGF analysis. P607 and P613 located inside the pathways have relatively high QGF values while P605, P610 and P613 located outside the pathways have low QGF values. Results obtained by two methods are basically the same, which verify the feasibility of the two methods.

\section{DISCUSSIONS}

\subsection{Application Effect}

Results obtained by quantitative grain fluorescence and EMT analysis have no geological meanings unless a fundamental value is given as a reference. In this study, we used P609 which has a commercial oil flow in the Shawan formation as the standard well to evaluate the sandstone carrier. The QGF index of the P609 is 4.91pc and the EMT is $3 \mathrm{~m}$. In the contour map of the QGF index, areas with index value higher than 4.6 can be regarded as the dominant migration pathways. In the contour map of the EMT, areas with thickness values higher than 3 can be regarded as the dominant migration pathways. Migration pathways of the sandstone obtained by two methods are shown in Fig. (7), in where the pathways' forms are very similar. The distribution of the oil reservoirs is consistent with the pathways' form, indicating that these two methods are practical for describing migration pathways. This suggests that the southern pathway controls the enrichment of the oil. On this basis, the area north of P612 is inferred as a potential oil-rich area where no big oil reservoir has been found. We used P602, having a commer- 
cial oil flow in the Cretaceous with the EMT of $3 \mathrm{~m}$, as the standard well to analyze the unconformity carriers. In the contour map of the EMT, areas with thickness value higher than $4 \mathrm{~m}$ can be regarded as the dominant migration pathway though P602 has no QGF data. Fig. (7) shows that the oil flow wells of the Cretaceous is mainly distributed inside or near the migration pathways. Though no large-scale oil reservoir has been found, area inside the pathways still has exploration potential. The identification of the dominant migration pathways is useful for narrowing the exploration area and increasing the success rate of the drillings.

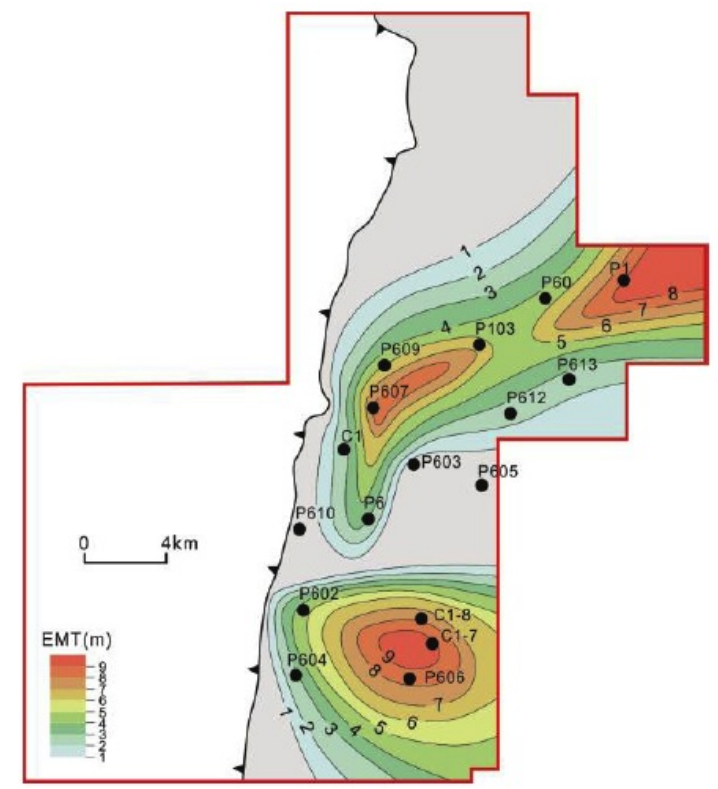

Fig. (6). Contour map of the EMT of the Unconformity Carrier.

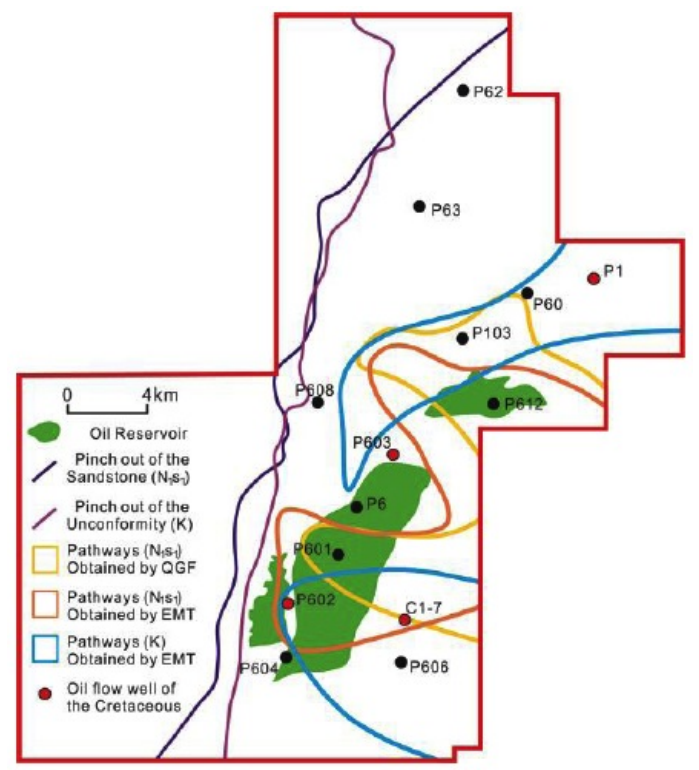

Fig. (7). Distribution map of the migration pathways obtained by two methods.

\subsection{Comparison and Analysis}

Quantitative grain fluorescence and EMT analysis can both analyze the sandstone and unconformity carrier and identify the dominant migration pathways. However, for different carrier media, the specific operations and procedures of each method are different. To make a correct evaluation of the sandstone carrier, precondition that the samples collected are located in the carrier interval is needed in the QGF analysis. The thickness of the sandstone carrier and its EMT in EMT analysis can be obtained from well logging reports and well logging diagrams. For unconformity carrier, the most fundamental work is the identification of the unconformity and the determination of the thickness. The samples of the QGF analysis and the statistics of the oil shows can determine that they are located inside the unconformity interval unless the thickness of the unconformity is determined. The standards of the unconformity identification are different in different regions. The establishment of standard should be based on the lithology, logging response and core analysis. Taking P607 as an example, the unconformity thickness is $25.5 \mathrm{~m}$ with $15 \mathrm{~m}$ rocks above the unconformity. If the rocks above the unconformity are incorrectly identified as $3 \mathrm{~m}$ or $7 \mathrm{~m}$, the EMT calculation and the following analysis are inevitably affected, which result in the mistakes in the migration pathways identification.

Each method has advantages and disadvantages; therefore, for same carrier media, we need mutual constraint from two methods to make a better analysis of the migration pathways. The basic work of the QGF analysis is sampling which determines the analysis effect. Sampling in the core is the best because of the well preservation of the rocks and the accuracy of the depth. Cutting samples may have inaccuracy in depth adjustment and mixing with cuttings in other depth interval. The distribution of the oil in thick sandstone interval is inhomogeneous, which results in the contingency of the oil enrichment in samples. The proper way of avoiding this problem is increasing the sampling density, that is, obvious oil show interval and non-oil show interval should be both densely sampled. However, the increase of the samples number would increase the workload and analysis time and reduce the timeliness of the study. EMT analysis is very simple and practicable to obtain the results. No sample collection and laboratory analysis is needed. It is convenient for researcher to modify and enrich the results and conclusion with new drilling data. However, the precondition of this method is that the oil residues in the carrier do not suffer damage. Premature hydrocarbon accumulation could result in the cracking of the hydrocarbon into gas as the temperature increased during the long buried history. Too much lightness of the oil (gas condensation) also reduces the oil show rank, impacting the application of EMT method. Therefore, the EMT method is feasible only when the accumulation period is not too early and the oil in the carrier is not too light or damaged. The well logging standards in different region are different; hence, in the application of this method, reasonable weighting values should be chosen according to the actual situation.

\section{CONCLUSION}

In this paper, we use QGF method and EMT method to study the hydrocarbon carrier and compare the results. The Chepaizi uplift in the west Junggar Basin (NW China) is 
selected as the application area. Sandstone carrier in the $\mathrm{Ne}$ ogene Shawan formation and unconformity carrier of the Cretaceous is studied by these two methods. The evaluations for same carrier with two quantitative methods obtain similar results, verifying their feasibility of application. Precondition that the samples collected are located inside the carrier interval, is needed in QGF analysis. Thickness of the sandstone carrier can be obtained from the logging reports. Proper sampling is the assurance of accurate results. For unconformity carrier, thickness of the carrier should be determined by systematic analysis of drilling data and logging data. Standards of oil shows are different in different regions; therefore, different geology characteristics need different weighting values in EMT method. The precondition of EMT method is that the oil is not too light and is well preserved.

\section{CONFLICT OF INTEREST}

The authors confirm that this article content has no conflict of interest.

\section{ACKNOWLEDGEMENTS}

We would like to thank Research Institute of Petroleum Exploration and Development for supporting this study and for granting permission to publish the results. We also thank Shengli Oil \& Gas field Company for providing drill data. Li Xiaoqing and Hao Bin are acknowledged for providing guidance and previous version.

\section{REFERENCES}

[1] K. Magara, Compaction and Fluid Migration, Practical Petroleum Geology, Elsevier, Amsterdam, 1978.

[2] F. Hao, H.Y. Zou, X.G. Li, and J.Q. Jiang, "Migration and occurrence of high wax oils in the Damintun depression, Northeast, China: Implication for primary controls of petroleum migration pathways in heterogeneous carrier beds", Journal of Petroleum Science and Engineering, vol. 67, pp. 105-115, 2009.

[3] X.R. Luo, "Simulation and characterization of pathway heterogeneity of secondary hydrocarbon migration", AAPG Bulletin, vol. 95, pp. 881-898, 2011.

[4] P. Ungerer, J. Burrus, B. Doligez, Y. Chenet, and F. Bessis, "Basin evaluation by integrated two-dimensional modeling of heat transfer, fluid flow, hydrocarbon generation, and migration", AAPG Bulletin, vol. 74, pp. 309-335, 1990.

[5] T.T. Schowalter, "Mechanics of secondary hydrocarbon migration and entrapment", AAPG Bulletin, vol. 63, pp. 723-760, 1979.

[6] J.C. Pratsch, "Gasfields, NW German basin: secondary migration as a major geologic parameter", Journal of Petroleum Geology, vol. 5, pp. 229-244, 1983.

[7] S. Hustoft, J. Mienert, S. Bunz, and H. Nouze, "High-resolution 3D-seismic data indicate focussed fluid migration pathways above polygonal fault systems of the mid-Norwegian margin", Marine Geology, vol. 245, pp. 89-106, 2007.

[8] R.C. Xin, H. Liu, and G.F. Li, "Incised valley filling deposits: an important pathway system for long-distance hydrocarbon migration - a case study of the Fulaerji Oilfield in the Songliao Basin", Petroleum Science, vol. 6, pp. 230-238, 2009.

[9] J.X. Yang, and R.J. Davies, "Gravity-driven faults: migration pathways for recycling gas after the dissociation of marine gas hydrates", Marine Geology, vol. 336, pp. 1-9, 2013.

[10] M.M. Thomas, and J.A. Clouse, "Scaled physical model of secondary oil migration”, AAPG Bulletin, vol. 79, pp. 19-29, 1995.

[11] R.E. Ewing, "Aspects of upscaling in simulation of flow in porous media", Advance Water Resources, vol. 20, pp. 349-358, 1997.
[12] D.A. Karlsen, and J.E. Skeie, "Petroleum migration, faults and overpressure: Part I. calibrating basin modeling using petroleum in traps: A review", Journal of Petroleum Geology, vol. 29, pp. 227256, 2006.

[13] P. Miller, S. Dasgupta, and D. Shelander, "Seismic imaging of migration pathways by advanced attribute analysis, Alaminos Canyon 21, Gulf of Mexico", Marine and Petroleum Geology, vol. 34, pp. 111-118, 2012.

[14] D.F. He, X.F. Chen, J. Kuang, L. Zhou, Y Tang, and D.G. Liu, "Development and genetic mechanism of chepaizi-mosuowan uplift in Junggar basin", Earth Science Frontiers, vol. 15, pp. 42-55, 2008.

[15] F.C. Xing, Y.C. Lu, C.H. Liu, and K. Xiang, "Structuralpaleogeomorphologic features of Chepaizi area and mechanism of their control on sandbodie", Oil and Gas Geology, vol. 29, pp. 79$83,2008$.

[16] X.D. Zhao, K. Xiang, G.H. Ye, S.C. Yang, S.Q. Zhang, and N.N. Chen, "Sequence stratigraphy framework analyses of the Neogene Shawan formation in Chepaizi area, Junggar basin", Science and Technology Review, vol. 28, pp. 89-94, 2010.

[17] S.C. Yang, X.M. Meng, N.N. Chen, S.Q. Zhang, and K. Xiang, "Depositional characteristics of Shawan formation in Neogene of Chepaizi area, Junggar Basin", Journal of China University of Petroleum, vol. 35, pp. 20-24, 2011.

[18] Y. Shen, and M.R. Li, "A discussion on the genesis of light and heavy oil distribution of inverted sequences in the Chepaizi Salient, the Junggar Basin”, Oil and Gas Geology, vol. 29, pp. 66-71, 2008.

[19] Y. Shen, D. Jia, H.L. Zhao, and X.L. Han, "Shawan formation pool-forming system and enrichment regular pattern in Chepaizi salient, western Junggar Basin, China”, Geological Bulletin of China, vol. 29, pp. 581-588, 2010.

[20] L.F. Liu, J.H. Meng, W.B. Wang, J. Jin, L. Wu, Y.D. Zhao, P. Wang, and D.M. Zhi, "Differences in geochemical characteristics of oils trapped in the upper and the lower series of strata of Chepaizi uplift along northwest margin of Junggar Basin and their significances", Journal of Jilin University, vol. 41, pp. 377-390, 2011.

[21] D.N. Zhao, X.M. Zhu, Y.L. Dong, D. Wu, W.F. Tao, and X. Wang, "Sequence stratigraphic framework of lower cretaceous and its main controlling factors in Chepaizi Area, Junggar Basin", Acta Sedimentologica Sinica, vol. 31, pp. 1070-1080, 2013.

[22] H. Jing, H. Jiang, and K. Xiang, "Key factors to control formation conditions of stratigraphic pools in Chepaizi area, the west of the Junggar basin", Petroleum Geology and Experiment, vol. 29, pp. 377-383, 2007.

[23] C.G. Su, and W.P. Zhong, "An analysis on the provenance of the Neogene Shawan Formation in the Chepaizi Salient of the Junggar Basin", Oil and Gas Geology, vol. 31, pp. 648-655, 2010.

[24] S.C. Tian, Z.M. Sun, J.H. Fu, J. Han, C.Y. Hu, "A discussion on dynamics and dynamic system for hydrocarbon migration and accumulation", Oil and Gas Geology, vol. 28, pp. 129-138, 2007.

[25] J. Luo, X. Zhuang, and X. Han, "Main factors controlling hydrocarbon accumulation in Neogene Shawan formation in Chepaizi swell of Junggar basin," Xinjiang Petroleum Geology, vol. 29, no. 1, pp. 45-47, 2008.

[26] K.Y. Liu, and P.J. Eadington, "Quantitative fluorescence techniques for detecting residual oils and reconstructing hydrocarbon charge history", Organic Geochemistry, vol. 36, pp. 1023-1036, 2005.

[27] S.M. Li, X.Q. Pang, K.Y. Liu, and X.L. Fu, "A new approach to discriminate oil fluid inclusions quickly quantitative grain fluorescence (QGF) techniques and its application", Petroleum Geology and Experiment, vol. 28, pp. 386-390, 2006.

[28] H. Jiang, W.J. Shi, J.Z. Qin, D. Rao, Y.M. Luo, and B.B. Xi, "The application of the quantitative grain fluorescence analysis to study the reservoir in the Tahe oilfield", Petroleum Geology and Experiment, vol. 32, pp. 201-204, 2010. 
[29] K.Y. Liu, and P.J. Eadington, "A new method for identifying secondary oil migration pathways", Journal of Geochemical Exploration, vol. 78-79, pp. 389-394, 2003.

[30] Y.Y. Wu, S.H. Wu, and Z.Q. Cai, Oil field geology, Beijing: Petroleum Industry Press, 2005, pp. 1-50.

[31] K.Y. Wu, M. Zha, and M. Hong, "Relationship of reservoir formation with unconformities and their geophysical respondent in the
Junggar Basin", Petroleum Geology and Experiment, vol. 25, pp. 328-332, 2003.

[32] W. Yin, Z.N. Chen, H. Xu, and Y.M. Xi, "Unconformity type and its significance in petroleum geology", Xinjiang Petroleum Geology, vol. 27, pp. 239-241, 2006.

[33] L.Q. Chen, "Estimation of the amount of erosion at unconformities in the last stage of the Eocene Sanduo period in the Subei Basin, China", Petroleum Science, vol. 6, pp. 383-388, 2009.

Received: January 25, 2015

Revised: March 01, 2015

Accepted: March 10, 2015

(C) Kun and Suyun; Licensee Bentham Open.

This is an open access article licensed under the terms of the Creative Commons Attribution Non-Commercial License (http://creativecommons.org/licenses/by-nc/4.0/) which permits unrestricted, non-commercial use, distribution and reproduction in any medium, provided the work is properly cited. 